\title{
Magnitude of Sex Differences in Dichotomous Ossification Sequences of the Hand and Wrist
}

\author{
STANLEY M. GARN, ANDREW K. POZNANSKI AND KAY E. LARSON \\ Center for Human Growth and Development, and Department of Radiology, \\ University of Michigan, Ann Arbor, Michigan 48104
}

\begin{abstract}
KEY WORDS Ossification sequence - Sex differences - Dichotomous sequences - Developmental order.

ABSTRACT Among the dichotomous (present/absent:absent/present) ossification sequences individually ascertained in 3059 boys and girls with at least one but not more than 27 ossification centers of the hand and wrist, 54 such sequences exhibit statistically-significant sex differences in frequency, 32 of them at the $1 \%$ confidence level or better. Analyzed by regions (rows and rays, epiphyses and round bones), ten centers, primarily distals and those of the first digit, account for the majority of the significant sex differences.
\end{abstract}

It is commonly stated that the order of hand ossification is the same in both sexes (Greulich and Pyle, '59; Schmid and Moll, '60). Such a generalization is derived from the mean ages at ossification, or from median ages of ossification, and is correct insofar as the mean or median orders are then much the same in both sexes. For the hand and wrist, the capitate, hamate and distal radius tend to be earliest in both boys and girls, and the trapezium, trapezoid and distal ulna tend to be latest in age at appearance (Garn et al., '67). Such cross-sectional examinations of ossification order reinforce the assumption that sex differences in ossification are primarily differences in timing, and that the male is to some extent a "delayed female" (cf. Garn et al., '71).

When postnatal ossification is individually analyzed, however, in terms of dichotomous (present/absent:absent/present) ossification sequences, ossification order then reveals itself as more complex (Garn et al., '66). There are far more individual dichotomous sequences than mean or median orders might suggest, and there are sex differences in the frequencies of many dichotomous pairs of ossification sequences. This is true even for the wrist region alone, with some seven postnatal nuclei if the round bones alone are counted, or nine including the distal epiphyses of the radius and ulna (Garn et al., '72; Poznanski, '74). The question is open, therefore, as to the extent of sex differences in the complete matrix of postnatal hand centers, some 28 in number (excluding the pisiform and the sesamoids). There is also interest in ascertaining the major sexual dimorphisms in postnatal ossification order, both for population comparisons, and for diagnostic purposes, with abnormalities of sex chromosome complement especially in mind.

To do this we have studied in great detail standardized hand-wrist radiographs of 3029 boys and girls of European derivation, all with one or more postnatal ossification centers present but less than 28 postnatal centers visible on the radiographs. From precoded presence/absence data, the frequencies of each dichotomous sequence involving every pair of centers was computer-calculated, using special computer programs. By way of example, the frequency of cases in which the triquetral was present but not the lunate, or the lunate was present but not the triquetral, was printed out for each sex separately, along with the difference in percentage $(d)$, and the significance calculated as a chisquared $\left(\chi^{2}\right)$ value. Dichotomous (present/ absent:absent/present) sequences whose differences were significant at the $5 \%$ level or better were then listed as in the first table (table 1), but neglecting the reciprocals, i.e., the isometric other half of the matrix.

Now as shown in table 1 , some 27 present-absent ossification sequences differed 
TABLE 1

Major sex differences in dichotomous ossification sequences

\begin{tabular}{|c|c|c|c|c|c|c|c|}
\hline & \multirow{2}{*}{$\begin{array}{l}\text { Sequence } \\
\text { and } \\
\text { centers }\end{array}$} & \multicolumn{2}{|c|}{ Boys } & \multicolumn{2}{|c|}{ Girls } & \multirow{2}{*}{$\begin{array}{c}\text { Sex } \\
\text { difference } \\
\text { in } \\
\text { percent } 2\end{array}$} & \multirow[b]{2}{*}{$\begin{array}{c}\text { Chi } \\
\text { squared } 3\end{array}$} \\
\hline & & $\begin{array}{c}\text { Total } \\
\text { N }\end{array}$ & $\begin{array}{l}\text { Percent } \\
\text { with } \\
\text { sequence }\end{array}$ & $\begin{array}{c}\text { Total } \\
\text { N } 1\end{array}$ & $\begin{array}{l}\text { Percent } \\
\text { with } \\
\text { sequence }\end{array}$ & & \\
\hline Dist IV & Met V & 65 & 49.2 & 21 & 14.3 & 34.9 & 6.65 \\
\hline Dist IV & Met I & 163 & 89.0 & 28 & 60.7 & 28.2 & 12.70 \\
\hline Dist $V$ & Met I & 169 & 32.5 & 50 & 8.0 & 24.5 & 10.60 \\
\hline Dist IV & Met IV & 69 & 27.5 & 23 & 4.3 & 23.2 & 4.17 \\
\hline Dist II & Met I & 175 & 33.1 & 56 & 10.7 & 22.4 & 9.56 \\
\hline Prox I & Met I & 127 & 47.2 & 39 & 25.6 & 21.6 & 4.86 \\
\hline Triq & Mid V & 338 & 49.7 & 108 & 29.6 & 20.1 & 12.50 \\
\hline Triq & Met I & 280 & 31.4 & 117 & 12.8 & 18.6 & 13.90 \\
\hline Mid V & Met I & 217 & 26.7 & 53 & 9.4 & 17.3 & 6.10 \\
\hline Dist III & Met I & 165 & 90.3 & 27 & 74.1 & 16.2 & 4.36 \\
\hline Dist IV & Prox I & 194 & 94.6 & 43 & 79.1 & 15.6 & 8.18 \\
\hline Triq & Dist II & 302 & 42.7 & 107 & 29.9 & 12.8 & 4.91 \\
\hline Triq & Dist V & 300 & 42.3 & 111 & 29.7 & 12.6 & 4.90 \\
\hline Triq & Prox I & 305 & 34.1 & 122 & 22.1 & 12.0 & 5.32 \\
\hline Lunate & Mid V & 505 & 16.6 & 269 & 5.2 & 11.4 & 19.70 \\
\hline Scaphoid & Trpzm & 241 & 55.6 & 213 & 44.6 & 11.0 & 5.04 \\
\hline Dist Ulna & Trpzm & 427 & 13.1 & 515 & 4.3 & 8.8 & 22.90 \\
\hline Lunate & Dist V & 500 & 11.8 & 264 & 3.8 & 8.0 & 12.50 \\
\hline Dist Ulna & Trpzd & 380 & 9.5 & 460 & 1.7 & 7.7 & 23.50 \\
\hline Lunate & Dist II & 485 & 10.9 & 261 & 3.4 & 7.5 & 11.50 \\
\hline Dist Ulna & Scaphoid & 413 & 8.5 & 471 & 2.3 & 6.1 & 15.60 \\
\hline Lunate & Prox I & 532 & 9.2 & 291 & 3.4 & 5.8 & 8.58 \\
\hline Prox V & Prox I & 189 & 100.0 & 54 & 94.4 & 5.6 & 6.56 \\
\hline Lunate & Met I & 520 & 7.5 & 302 & 2.0 & 5.5 & 10.20 \\
\hline Dist I & Dist II & 250 & 99.6 & 87 & 95.4 & 4.2 & 5.17 \\
\hline Lunate & Trpzd & 702 & 98.3 & 390 & 95.4 & 2.9 & 6.87 \\
\hline Lunate & Trpzm & 687 & 98.7 & 354 & 96.3 & 2.4 & 5.21 \\
\hline
\end{tabular}

${ }_{1}$ Number of individuals showing pairs of sequences involving the centers in question, i.e., distal IV/metacarpal V: metacarpal V/distal IV.

2 For the reciprocals of these sequences, the sex differences are in the opposite direction.

3 Values in excess of 3.8 significant at $p=0.05$ or better.

significantly between the sexes, all with $x^{2}$ values of 3.8 and greater. This represents half the total matrix, since the alternate sequences in each case were also significantly different between the sexes. Against the theoretical maximum of 756 dichotomous sequences, the full number of 54 was significant by sign test (i.e., 54 as against the chance number 38 ). The excess of observed sex differences in postnatal ossification sequence beyond chance is further increased both by examination of the distribution of chi-squared values (11 of them in excess of 10.0, and one as high as 23.5), and by the 34 with $p$ values better than 0.01 . So, there are far more sex differences in dichotomous ossification sequences than chance alone would allow, and certainly many more than the six that could be expected at the $p=0.01$ level or better for the 650 sequences actually observed in this sample of 3029 boys and girls, drawn from a far larger number through age 11.0.

Some of the largest sex differences in dichotomous ossification sequences are listed (in descending order of magnitude) and with attendant chi-squared values, all in table 1. They include distal IV/metacarpal V, with a sex difference of $35 \%$; distal IV/metacarpal I, with a sex difference of $28 \%$; and distal $\mathrm{V} /$ metacarpal I (a $25 \%$ sex difference) down through lunate/trapezium, with a significant sex difference of only $2.4 \%$. In all, seven of the 27 statistically significant sequences involved the distals and with sex differences generally exceeding $10 \%$. All the sequences described were significant at the $p=0.05$ level or better, with individual values of chi-squared as high as 22 and 23.

Now the details of table 1 , listing statistically-significant sexual dimorphisms in 


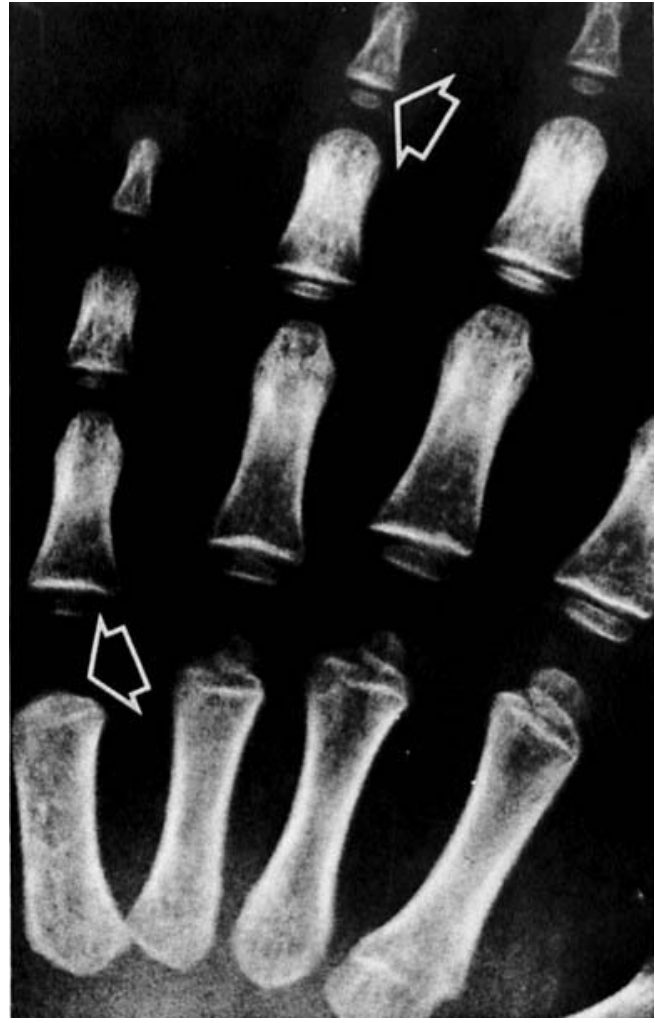

Fig. 1 Postero-anterior hand radiograph of a 4.8 year old boy showing the dichotomous (present-absent) ossification sequence with the largest sex difference $(49 \%$ in boys, $14 \%$ in girls). The arrows point to the well-developed proximalepiphysis of distal IV, and the as-yet uncalcified distal epiphysis of metacarpal $V$. As with the other statistically-significant sex differences listed in table 1 , the converse or reciprocal dichotomous sequences are more common in girls.

dichotomous ossification sequences in descending order of magnitude, raise the question as to whether particular postnatal nuclei of the 28 considered are disproportionately involved. Involvement of the triquetral, with its reputed wide variability in ossification timing may well be examined, as well as the possibility that particular rows (distal, middle, proximal) or that particular rays or digits (I, II, III, etc.) may be represented among the dimorphic sequences more often than chance allows.

We have explored this latter possibility, by listing the 28 centers, one by one, both with respect to chance representation and with respect to actual representation both as present and absent. Out of the 54 possibilities thus considered, any given center would be expected to be represented approximately twice (i.e., 28 centers and 54 possibilities).

So as shown in table 2, some of the 28 centers are involved in ossification sequence dimorphisms more often than might be expected, and some are represented less often than might be expected. The distals, by way of example, are surely over-represented, while the middles and proximals are under-represented. To fur-

TABLE 2

Regional analysis of significant sex differences in ossification sequences 1

\begin{tabular}{|c|c|c|c|}
\hline $\begin{array}{l}\text { Center or } \\
\text { region }\end{array}$ & $\begin{array}{c}\text { Expected } \\
\text { no. }\end{array}$ & $\begin{array}{c}\text { Observed } \\
\text { no. }\end{array}$ & Difference \\
\hline Distal V & 2 & 3 & $1 *$ \\
\hline Distal IV & 2 & 4 & $2 *$ \\
\hline Distal III & 2 & 1 & -1 \\
\hline Distal II & 2 & 4 & $2^{*}$ \\
\hline Distal I & 2 & 1 & $-\overline{1}$ \\
\hline Distals & 10 & 13 & 3 \\
\hline Middle V & 2 & 3 & $1 *$ \\
\hline Middle IV & 2 & 0 & -2 \\
\hline Middle III & 2 & 0 & -2 \\
\hline Middle II & 2 & 0 & -2 \\
\hline Middles & 8 & 3 & -5 \\
\hline Proximal V & 2 & 1 & -1 \\
\hline Proximal IV & 2 & 0 & -2 \\
\hline Proximal III & 2 & 0 & -2 \\
\hline Proximal II & 2 & 0 & $-\overline{2}$ \\
\hline Proximal I & 2 & 5 & $3 *$ \\
\hline Proximals & 10 & 6 & -4 \\
\hline Metacarpal V & 2 & 0 & -2 \\
\hline Metacarpal IV & 2 & 1 & $-\overline{1}$ \\
\hline Metacarpal III & 2 & 1 & -1 \\
\hline Metacarpal II & 2 & 0 & -2 \\
\hline Metacarpal I & 2 & 8 & $6 *$ \\
\hline Metacarpals & 10 & 10 & 0 \\
\hline Hamate & 2 & 0 & -2 \\
\hline Capitate & 2 & 0 & -2 \\
\hline Trapezoid & 2 & 2 & 0 \\
\hline Trapezium & 2 & 3 & $1 *$ \\
\hline Triquetral & 2 & 5 & $3 *$ \\
\hline Lunate & 2 & 7 & $5 ;$ \\
\hline Scaphoid & 2 & 2 & 0 \\
\hline Carpals & 14 & 19 & 5 \\
\hline Dist Ulna & 2 & 0 & -2 \\
\hline Dist Radius & 2 & 3 & $1 *$ \\
\hline Forearm & 4 & 3 & 1 \\
\hline
\end{tabular}

1 Based on 27 pairs of centers in table 1 . In all, ten centers (designated by asterisks) account for $83 \%$ of the significant sex differences, against $36 \%$ that would be expected by chance. $\left(\chi^{2} \cong 50\right)$ 
ther continue the regional and anatomical analysis by rows and rays (or digits), the first digit or ray is well-represented among the sex differences in post-natal ossification sequences. As a group, the carpals are over-represented, i.e., dichotomous sequences involving the carpals are notably different between the sexes. All of this is pictured for clarity in figure 2, wherein the contributions of the distals (distals I-V) and of ray I (distal to proximal and metacarpal) are shown, along with the triquetral and the lunate. The ten centers indicated by tone on the figure are involved in $83 \%$ of the 54 sequences that significantly differ between the sexes (cf. fig. 2 and table 1).

In summation then, 27 dichotomous (present/absent) ossification sequences show statistically significant sexual dimorphisms in the half-matrix, and therefore 54 in the full matrix of present-absent, absent-present sequences among 1803 boys and 1226 girls of European derivation, with at least one but not more than 28 postnatal centers. The distribution of chisquared values and levels of probability (p) indicates that many more ossification sequence differences are statistically significant than chance alone might suggest. Clearly, the order of ossification as individually analyzed is not the same for both sexes (cf. Garn et al., '72). The sequence dimorphisms of exceptional magnitude merit investigation in karyotypic abnormalities involving the sex chromosome (cf. Poznanski et al., "71) particularly in the $X Y Y$ and the XXY and XXXY karyotypes.

It remains to be seen whether the same ossification sequence dimorphisms or sexual dimorphisms involving the same distal centers and centers of the first digit (ray I) characterize other populations of African and Meso-American descent. Attention may also be directed to the dimensional and developmental progress of boys and girls showing dichotomous sequences characteristic of the other sex, and to nutritional and other influences that may possibly alter the ossification order characteristic of a sex. It is our continuing observation that rare and atypical ossification sequences (for sex and race) are associated with statural reductions and other evidences of developmental delay. It is of interest to ascertain whether a

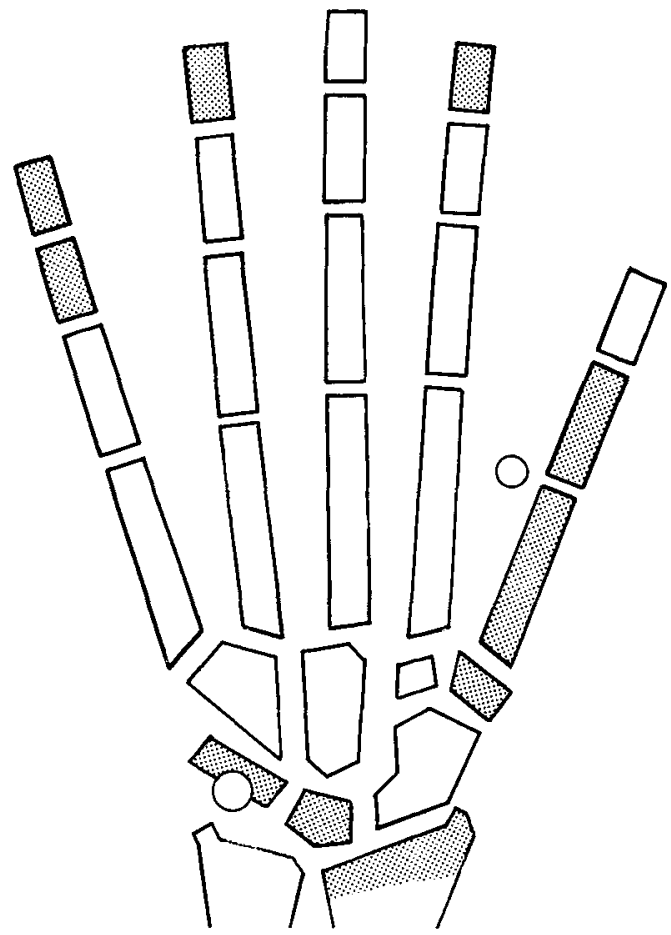

Fig. 2 Graphic representation, using a stylized hand, showing the anatomical location of postnatal ossification centers that differ most in ossification order between the sexes. These include distals (among the rows), the first digit (among the rays), three carpal centers, and the distal radius. In all, the ten centers indicated by shading account for $83 \%$ of the significant sex differences in dichotomous ossification sequences as against the $36 \%$ that would be expected by chance.

boy or a girl evidencing sequences peculiar to the opposite sex also differs from expectancy in the magnitude and direction of other sexual dimorphisms.

\section{ACKNOWLEDGMENTS}

This study was supported in parts by Contract HD-07134 with the National Institutes of Child Health and Human Development, Washington, D.C., Contract NIH-HSM-1 10-69-22 with the Center for Disease Control, Atlanta, Georgia, Grant RG73-9(2) with the James Picker Foundation on recommendation of the Committee on Radiology, National Academy of Science, National Research Council, Washington, D.C., and Contract MC-R-39005006-0 from Maternal and Child Health Services HSMHA, Rockville, Maryland. We 
thank Dr. George Owen, M.D. for his generosity in letting us use his survey data. We extend our appreciation to Ken Guire and Richard N. Miller for their assistance in data analysis and efforts in developing techniques of data analysis suitable to $28 \times 28$ matrices, and to Dixie Farquharson for her efforts in the manuscript preparation.

\section{LITERATURE CITED}

Garn, S. M., A. K. Poznanski and J. M. Nagy 1971 The operational meaning of maturity criteria. Am. J. Phys. Anthrop., 35: 319-325.

Garn, S. M., C. G. Rohmann, T. Blumenthal and C. S. Kaplan 1966 Developmental communalities of homologous and non-homologous body joints. Am. J. Phys. Anthrop., 25: 147-151.
Garn, S. M., C. G. Rohmann and F. N. Silverman 1967 Radiographic standards for postnatal ossification and tooth calcification. Med. Radiog. and Photog., 43: 45-65.

Garn, S. M., S. T. Sandusky, R. L. Miller and J. M. Nagy 1972 Developmental implications of dichotomous ossification sequences in the wrist region. Am. J. Phys. Anthrop., 37: 111-115.

Greulich, W. W., and S. I. Pyle 1959 Radiographic Atlas of Skeletal Development of the Hand and Wrist. Ed. 2. Stanford University Press, Stanford, Calif.

Poznanski, A. K. 1974 The Hand in Radiologic Diagnosis. W. B. Saunders, Philadelphia, Pa.

Poznanski, A. K., S. M. Garn, L. R. Kuhns and S. T. Sandusky 1971 Dysharmonic maturation of the hand in the congenital malformation syndromes. Am. J. Phys. Anthrop., 35: 417-432.

Schmid, F., and H. Moll 1960 Atlas den Normalen und Pathologischen Handskelettentwicklung. Springer-Verlag, Berlin. 